\title{
Meaning in Life among New Mothers before and during the COVID-19 Pandemic: The Role of Mothers' Marital Satisfaction and Perception of the Infant
}

\author{
Miriam Chasson $^{1} \cdot$ Ofir Ben-Yaakov ${ }^{1}$. Orit Taubman - Ben-Ari ${ }^{1}$
}

Accepted: 14 March 2021 / Published online: 23 March 2021

(c) The Author(s), under exclusive licence to Springer Nature B.V. 2021

\begin{abstract}
On the assumption that existential questions may arise in the face of the transition to motherhood in the shadow of a global crisis, we sought to compare the levels of presence of meaning and search for meaning in life between two samples of new mothers: one recruited before the outbreak of COVID-19, and the other during the pandemic. In addition, we examined the associations between mother's marital satisfaction and perception of the infant on the one hand, and the two aspects of meaning in life on the other, investigating whether these variables mediate the link between research group and meaning in life. The results indicate that mothers reported significantly higher perception of infant's warmth and presence of meaning before than during the pandemic. Furthermore, they displayed greater marital satisfaction and more search for meaning during the pandemic than prior to it. For the whole sample, higher marital satisfaction and perception of infant's warmth were related to higher presence of meaning, and lower marital satisfaction and perception of the infant's invasiveness were related to higher search for meaning. Finally, mother's marital satisfaction and perception of the infant fully mediated the relationship between the research group and the two aspects of meaning in life. These findings are significant in that they provide, for the first time, evidence of changes in meaning in life among new mothers in a crisis situation, along with the importance of their perceptions of their relationships with the infant and spouse under these circumstances.
\end{abstract}

Keywords COVID-19 $\cdot$ Mothers $\cdot$ Meaning in life $\cdot$ Marital satisfaction $\cdot$ Perception of the infant

\section{Introduction}

Since the outbreak of COVID-19 in Wuhan, China in December 2019, the pandemic has taken a heavy toll on individuals around the globe, affecting not only physical health, but also social interactions, economic activity, and mental health. Like many other countries,

Orit Taubman - Ben-Ari

taubman@biu.ac.il

1 The Louis and Gabi Weisfeld School of Social Work, Bar-Ilan University, 52900 Ramat Gan, Israel 
Israel is attempting to curb the rise in morbidity and mortality by imposing lockdowns and social distancing, while at the same time struggling to manage the heavy economic damage and rising unemployment during a period of considerable change and ambiguity.

Crisis events, such as the pandemic, tend to shock and undermine safe, familiar reality as we know it. They are likely to increase distress and may lead to psychological symptoms such as depression and anxiety, as recent studies have found in the current situation (e.g., Ahorsu et al., 2020; Choi et al., 2020; Gao et al., 2020; Gómez-Salgado et al., 2020). At the same time, the crisis may have other salient consequences, as they expose the individual to existential concerns about the value and meaning of life (Steger et al., 2006; Van Tongeren et al., 2017). Meaning in life is composed of two dimensions: the presence of meaning, expressed in a sense of coherence, purpose, and significance toward one's existence, surrounding events, and the comprehensibility of reality; and search for meaning, aroused by feelings of emptiness and lack of understanding of life's value and purpose (Boullion et al., 2020; Steger et al., 2006). Studies suggest that whereas well-being and happiness are associated with the presence of meaning in life, distress is related to the search for meaning (Crego et al., 2020; Li et al., 2020; Steger et al., 2008). In addition, a study examining the presence of meaning in life in the shadow of COVID-19 found a positive association with hope, which in turn was negatively associated with stress and anxiety (Trzebiński et al., 2020). In other words, presence of meaning seems to play an important role in dealing with the current crisis.

Normative life events, such as the transition to parenthood, also tend to raise existential questions (Nelson et al., 2014; Taubman - Ben-Ari, 2012). Although this transition is highly significant for both parents, the changes experienced by women after the birth of their first child seem to be most pronounced, since it is they who undergo the pregnancy and childbirth and typically function as the primary caregiver for the baby. Moreover, while most new mothers in Israel return to work after a maternity leave lasting 14 weeks to six months, fathers do not tend to take paternity leave, usually staying at home with the mother and infant for only a few days after childbirth. The transition to motherhood may evoke a strong sense of meaning in life insofar as the mother views her new role as important, valuable, and worthwhile, and accordingly perceives the demands placed upon her as logical and coherent. However, she might also feel that she has lost her previous identity, leading to a lower sense of meaning in life or an attempt to find new value and meaning (Morse \& Steger, 2019).

If the transition to motherhood triggers existential concerns in routine times, the impact of this dramatic change in a woman's life may be intensified by a time of crisis. Thus, during the current pandemic, new mothers' perception of meaning in life may be shaken even more, causing them to feel a higher or lower level of presence of meaning and increasing or decreasing their search for meaning.

In addition to external circumstances, other variables have been related to the sense of meaning in life, as well as to the ability to cope with stress and crisis. One of these is the individual's perception of their interpersonal relationships with the people close to them (Demirbaş-Çelik \& Keklik, 2019; Goodman et al., 2019; O’Donnell et al., 2014; Van Bavel et al., 2020). For new mothers, the closest relationships are generally with the spouse and the child. However, to the best of our knowledge, no prior study has examined the role played by the mother's marital satisfaction and perception of the infant in her assessment of meaning in life at a time of crisis, and specifically in the shadow of the COVID-19 pandemic.

Marital satisfaction reflects the individual's subjective perception of various aspects of their marital relationship, such as the level of emotional and instrumental support and 
intimacy (Hendrick, 1988). The marital relationship, and the level of satisfaction from it, are dynamic and may undergo changes in different periods of life (Keizer \& Schenk, 2012). An external crisis may pose a challenge for this relationship, with the stress and uncertainty it generates leading to conflicts and tension between the couple and consequently to a decrease in marital quality (Prime et al., 2020). On the other hand, coping jointly with the crisis may bring the couple closer (Van Bavel et al., 2020). The same holds true for the transition to parenthood (Cowan \& Cowan, 2000), with some studies finding a decrease in marital satisfaction in the wake of this transition (Leavitt et al., 2017; Mickelson \& Joseph, 2012), and others reporting an increase (Doss et al, 2009; Schulz et al., 2006).

The literature indicates an association between a positive marital relationship and greater presence of meaning in life (Kalantarkousheh \& Hassan, 2010; O'Donnell et al., 2014). However, we are not aware of any studies that have examined the connection between marital satisfaction and search for meaning in general, or in the transition to parenthood in particular.

Perception of the infant refers to the way parents interpret their child's behaviors (Oates $\&$ Gervai, 2019). A perception of warmth indicates that the parent feels that the infant desires their closeness and expresses affection toward them, and they view the motives behind the child's behavior in a positive light. In contrast, a perception of invasiveness means that they perceive the infant to be difficult, overly demanding, and dominating, and they tend to interpret the infant's behavior negatively (Oates et al., 2018; Slade et al., 2005). Studies show that a positive perception of the infant is related to better psychological wellbeing for the parent, while a negative perception is related to distress (Davies et al., 2008; Lefkovics et al., 2018; Nath et al., 2019). In addition, a positive perception of the child has been associated with a greater sense of presence of meaning in life (Nelson et al., 2014). To the best of our knowledge, however, no previous studies have examined the relationship between the mother's perception of the infant and the search for meaning.

\subsection{The Current Study}

Although meaning in life appears to be an important factor in coping with stress and crisis, there is a lack of knowledge regarding its role for women faced with the two-fold challenge of an external crisis and the transition to motherhood. We sought to fill this gap by examining meaning in life among new mothers during the COVID-19 pandemic. To this aim, we compared two samples of new mothers during the first year after childbirth: one recruited in early 2019 before the outbreak of COVID-19 (Group 1); and the second recruited in April, 2020 during the pandemic (Group 2). This enabled us to examine differences not only in the level of meaning in life and search for meaning, but also in the contributors to these variables in the two periods. Furthermore, in view of the literature, we investigated the effect of mother's marital satisfaction and perception of the infant on presence and search for meaning, as well as whether these variables mediate the association between research group and meaning in life.

We hypothesized that the higher the mother's marital satisfaction and perception of the infant's warmth, the greater presence of meaning she will report in both samples. In addition, given the lack of previous research on which to rely, the following questions were examined exploratively:

1 Are there differences in the level of presence and search for meaning, marital satisfaction, and perception of the infant between the two groups? 
2 Is there an association between the mother's marital satisfaction and perception of the infant on the one hand, and the search for meaning on the other?

3 Do marital satisfaction and perception of the infant mediate the relationship between research group and the presence and search for meaning?

\section{Method}

\subsection{Participants and Procedure}

Following approval of the study protocol by the university's Institutional Review Board, convenience samples of Israeli mothers of infants aged 3 to 12 months were recruited in two phases: from August 2018 to May 2019 for a larger scale research project on new parents; and from April 8-13, 2020 during the peak of the first wave of the COVID-19 outbreak in Israel. In both cases, a request to participate in the study was posted on social media groups for mothers and was directed specifically at mothers whose first child was no more than 12 months old. A link to an electronic version of the questionnaire was provided. The opening page ensured anonymity and confidentiality, and explained that the mother could cease to participate at any stage should she wish to do so. The mothers were also informed that if they felt any distress during or after completing the questionnaire, they could call or email the researchers, whose contact details were supplied. Participants were considered eligible for the study if they were first-time mothers of babies aged 3-12 months and indicated that they could complete questionnaires in Hebrew. Response rate was $75 \%$ for both samples.

The final sample consisted of 1,138 mothers: 685 in Group 1 (before the pandemic), and 453 in Group 2 (during the pandemic). For the sample as a whole, mother's age ranged from 21 to $39(M=29.78, S D=3.86)$, and infant's age from 3-12 months $(M=7.02$, $\mathrm{SD}=2.74)$. All the participants were married or in a spousal relationship; $73 \%$ had an academic degree, and the rest had a high school or post-high school diploma; $28.7 \%$ defined their income as average, $29.1 \%$ as above average, and $42.3 \%$ as below average; and $56.7 \%$ defined their health status as very good, $34.6 \%$ as good, and the rest (8.6\%) as poor.

A series of t-tests performed to examine differences in background variables between the groups indicated that the mothers in Group 2 were slightly older than those in Group 1 $(\mathrm{M}=30.83, \mathrm{SD}=3.58 ; \mathrm{M}=29.09, \mathrm{SD}=3.88$, respectively $), \mathrm{t}(1138)=-7.33, p<0.001$, and had a slightly higher level of education $(\mathrm{M}=4.85, \mathrm{SD}=1.16 ; \mathrm{M}=4.49, \mathrm{SD}=1.35$, respectively), $\mathrm{t}(1138)=-4.64, p<0.001$. On the other hand, the mothers in Group 1 reported a higher economic status than those in Group $2(\mathrm{M}=2.06 . \mathrm{SD}=0.71 ; \mathrm{M}=1.61, \mathrm{SD}=0.92$, respectively), $\mathrm{t}(1138)=9.15, p<0.001$. These differences were controlled for in the analysis.

\subsection{Instruments}

Meaning in Life Questionnaire (MLQ; Steger et al., 2006), consisting of 10 items assessing meaning in life on two dimensions: presence of meaning (5 items; e.g., "My life has a clear sense of purpose"); and search for meaning (5 items; e.g., "I am searching for meaning in my life"). Responses are indicated on a 7-point scale from 1 (absolutely untrue) to 7 (absolutely true). Cronbach's $\alpha$ for the original questionnaire was 0.88 for presence of meaning and 0.90 for search for meaning. In the current study, Cronbach's $\alpha$ was 0.82 for presence 
of meaning and 0.89 for search for meaning. Each participant was assigned a score for each dimension equal to the mean of their responses to the relevant items, with higher scores indicating a higher level of that dimension of meaning in life.

Marital Satisfaction (RAS; Hendrick, 1988), containing 7 items (e.g., "How often does your partner meet your needs?"). Responses are marked on a 7-point Likert scale from 1 (strongly disagree) to 7 (strongly agree). The internal consistency reported for the original scale is 0.86 (Hendrick, 1988), and was 0.89 in the present study. A score was assigned to each participant by totaling her responses to all items, with higher scores indicating greater satisfaction with the marital relationship.

Mothers' Object Relations Scale-Short Form (MORS-SF; Oates et al., 2018), used to assess the mother's perception of her infant. The 14-item questionnaire was developed to identify potential areas of difficulty in the early mother-child relationship by measuring two factors: infant's perceived emotional warmth (e.g., "My baby is affectionate towards me"), and infant's perceived invasiveness (e.g., "My baby wants too much attention"). Responses are indicated on a 6-point scale from 0 (never) to 5 (always). The instrument's axis items have been shown to possess stable and internally coherent properties (Oates et al., 2018), with an internal reliability of 0.90 found for both dimensions in a previous study (McDonald et al., 2011). In the current study, Cronbach's alpha was 0.79 for warmth and 0.71 for invasiveness. A score for each dimension was calculated by averaging the participant's responses to all relevant items, with higher scores indicating a greater perception of warmth or invasiveness.

A sociodemographic questionnaire was used to obtain information on the mother's background characteristics, including age, education, economic status, and health, as well as information about the delivery (gestation week, type of delivery) and the infant (birth weight, age).

\subsection{Data Analysis}

Analysis was conducted using SPSS (ver. 24). In the first stage, t-tests were computed to examine differences in the study variables between the two groups of mothers (before and during the pandemic). In the second stage, Pearson correlations were computed between the background characteristics and study variables. Finally, PROCESS analysis (Hayes, 2017; model 6) was used to identify multiple indirect effects and determine whether mother's marital satisfaction and perception of the infant mediated the associations between research group and the presence and search for meaning, while controlling for the background characteristics as covariates. Indirect pathways included both standard triple paths $(\mathrm{IV} \rightarrow \mathrm{M} \rightarrow \mathrm{DV})$ and quadratic paths (IV $\rightarrow \mathrm{M} 1 \rightarrow \mathrm{M} 2 \rightarrow \mathrm{DV})$. The decision criterion for a significant indirect effect was based on the $95 \%$ confidence interval, which resulted from bootstrap resampling $(n=10,000$ repeats), that is, when $95 \%$ of estimated indirect effects differed from zero (Hayes, 2017).

\section{Results}

\subsection{Differences in the Study Variables Before and During the Pandemic}

The means and standard deviations of the study variables by research group, along with the results of the t-tests, appear in Table 1. As Table 1 shows, Group 1 reported significantly 
Table 1 Means, standard deviations, and t-tests for the study variables by group

\begin{tabular}{|c|c|c|c|c|c|}
\hline & \multicolumn{2}{|c|}{$\begin{array}{l}\text { Group 1- } \\
\text { Before the } \\
\text { pandemic } \\
(\mathrm{n}=685)\end{array}$} & \multicolumn{2}{|c|}{$\begin{array}{l}\text { Group 2- } \\
\text { During the } \\
\text { pandemic } \\
(\mathrm{n}=453)\end{array}$} & \multirow[t]{2}{*}{$\mathrm{t}$} \\
\hline & M & SD & M & SD & \\
\hline Marital satisfaction & 5.62 & 1.13 & 5.80 & 0.99 & $-2.80^{* *}$ \\
\hline Infant's warmth & 4.98 & 0.64 & 4.88 & 0.58 & $2.52^{* *}$ \\
\hline Infant's invasiveness & 2.35 & 0.67 & 2.42 & 0.63 & -1.78 \\
\hline Presence of meaning & 5.40 & 1.01 & 5.24 & 1.06 & $2.40^{*}$ \\
\hline Search of meaning & 4.45 & 1.47 & 4.66 & 1.35 & $-2.46^{*}$ \\
\hline
\end{tabular}

higher perception of infant's warmth and presence of meaning than Group 2. On the other hand, Group 2 displayed greater marital satisfaction and more search for meaning than Group 1.

\subsection{Associations between Background Characteristics and Study Variables}

The results of the Pearson correlations between the background and study variables for the whole sample are presented in Table 2. As can be seen from Table 2, age, education, and economic status were significantly interrelated. In addition, older age was associated with lower perception of infant's warmth and higher presence of meaning in life. Higher education was associated with lower perception of infant's warmth, higher perception of infant's invasiveness, and higher search for meaning, while higher economic status was associated with lower search for meaning. In addition, greater marital satisfaction was associated with higher perception of infant's warmth, lower perception of infant's invasiveness, higher presence of meaning, and lower search for meaning. Higher perception of infant's warmth was associated with lower perception of infant's invasiveness and higher presence of meaning, and higher perception of infant's invasiveness was related to lower presence of

Table 2 Pearson correlations between demographic and personal resources and presence and search of meaning in the whole sample

\begin{tabular}{|c|c|c|c|c|c|c|c|c|}
\hline & 1 & 2 & 3 & 4 & 5 & 6 & 7 & 8 \\
\hline 1. Age & - & $0.35 * * *$ & $0.18 * * *$ & -0.04 & $-0.15^{* * *}$ & -0.001 & $0.09 * *$ & -0.04 \\
\hline 2. Education & & - & $0.21 * * *$ & -0.006 & $-0.20 * * *$ & $0.11 * * *$ & -0.03 & $0.08 * *$ \\
\hline 3. Economic status & & & - & .02 & -0.04 & 0.03 & -0.02 & $-0.06^{*}$ \\
\hline 4. Marital satisfaction & & & & - & $0.06^{*}$ & $-0.14 * * *$ & $0.25 * * *$ & $-10 * *$ \\
\hline 5. Infant's warmth & & & & & - & $-0.13^{* * *}$ & $0.26^{* * *}$ & 0.006 \\
\hline 6. Infant's invasiveness & & & & & & - & $-0.21 * * *$ & $0.11 * * *$ \\
\hline 7. Presence of meaning & & & & & & & - & $-10 * *$ \\
\hline 8. Search for meaning & & & & & & & & - \\
\hline
\end{tabular}

$* p<.05, * * p<.01, * * * p<.001$ 
Table 3 Total, direct, and indirect effects between group and presence of meaning

\begin{tabular}{|c|c|c|c|c|}
\hline & Effect & SE & $\mathrm{t}$ & $95 \% \mathrm{BC} \mathrm{CI}$ \\
\hline Total effect of group on presence of meaning & -0.12 & 0.07 & -1.88 & $-0.26,0.005 \mathrm{~ns}$ \\
\hline Direct effect of group on presence of meaning & -0.15 & 0.06 & $-2.36^{*}$ & $-0.27,-0.02$ \\
\hline Indirect effect via marital satisfaction & 0.05 & 0.02 & & $0.02,0.09$ \\
\hline Indirect effect via infant's warmth & -0.01 & 0.01 & & $-0.04,0.01 \mathrm{~ns}$ \\
\hline Indirect effect via infant's invasiveness & -0.02 & 0.01 & & $-0.04,-0.004$ \\
\hline Indirect effect via marital satisfaction and infant's warmth & 0.003 & 0.002 & & $-0.0003,0.008 \mathrm{~ns}$ \\
\hline $\begin{array}{l}\text { Indirect effect via marital satisfaction and infant's invasive- } \\
\text { ness }\end{array}$ & 0.005 & 0.002 & & $0.002,0.011$ \\
\hline Indirect effect via infant's warmth and invasiveness & -0.001 & 0.001 & & $-0.004,0.0007 \mathrm{~ns}$ \\
\hline $\begin{array}{l}\text { Indirect effect via marital satisfaction, infant's warmth, and } \\
\text { infant's invasiveness }\end{array}$ & 0.0002 & 0.0002 & & $0.0000,0.0007$ \\
\hline
\end{tabular}

$\mathrm{ns}=$ not statistically significant (as evidenced by a bootstrap confidence interval that straddles zero)

$*<0.05$

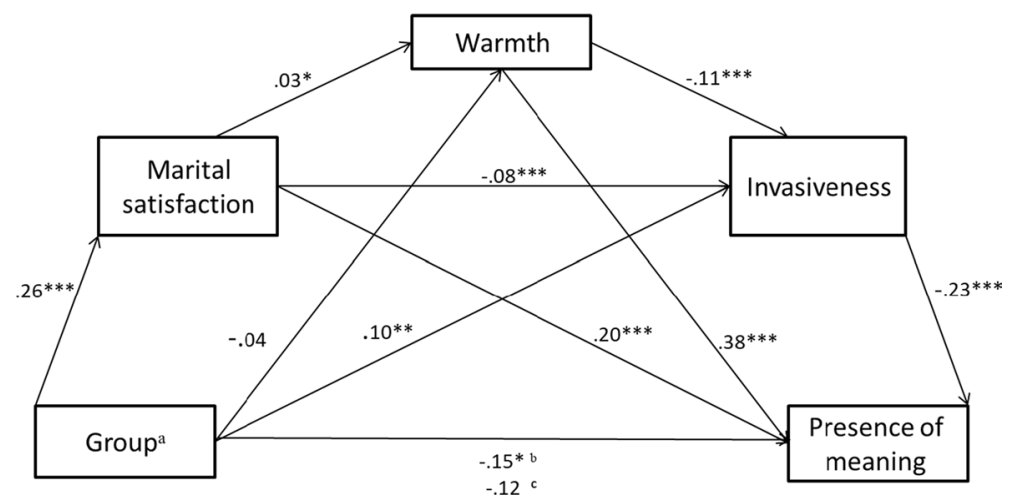

Fig. 1 Indirect Effects between Group and Presence of Meaning: Beta Weights and Standard Errors. Note ${ }^{\mathrm{a}} 0=$ before the pandemic, $1=$ during the pandemic; ${ }^{\mathrm{b}}$ Direct effect; ${ }^{\mathrm{c}}$ Total effect

meaning and higher search for meaning. Finally, higher presence of meaning was related to lower search for meaning.

\subsection{Indirect Effects between Research Group and Meaning in Life}

The results of the multiple mediation analysis appear in Table 3 and Figs. 1 and 2. As can be seen, a significant direct effect of research group was found on presence of meaning $(\beta=-0.15, \mathrm{SE}=0.06, \mathrm{t}(1133)=-2.36, p<0.05)$, so that greater presence of meaning was reported before than during the pandemic. However, this effect was insignificant in the presence of marital satisfaction, perception of infant's warmth, and perception of infant's invasiveness as mediators, indicating complete mediation. In other words, the effect of research group on presence of meaning was completely expressed indirectly through these mediating variables, meaning that the total effect was due mainly to the indirect mediations. 


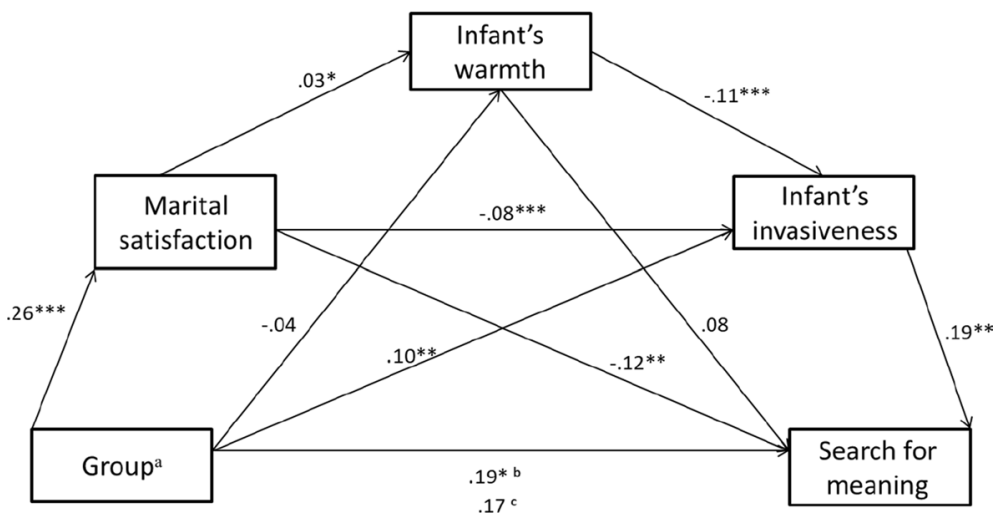

Fig. 2 Indirect Effects between Group and Search for Meaning: Beta Weights and Standard Errors. Note: ${ }^{\mathrm{a}} 0=$ before the pandemic, $1=$ during the pandemic; ${ }^{\mathrm{b}}$ Direct effect; ${ }^{\mathrm{c}}$ Total effect

As shown in Table 3 (see also Fig. 1), four significant paths of indirect associations between research group and presence of meaning were found. First, the bootstrapped indirect effect of research group on presence of meaning through marital satisfaction was significant, $(\beta=0.05, \mathrm{SE}=0.02, \mathrm{BC} \mathrm{CI}[0.02,0.09])$. That is, during the pandemic, mothers reported higher marital satisfaction, which in turn was associated with greater presence of meaning. The bootstrapped indirect effect of research group on presence of meaning via invasiveness was also significant $(\beta=-0.02, \mathrm{SE}=0.01, \mathrm{BC} \mathrm{CI}[-0.04,-0.004])$, so that, during the pandemic, mothers reported a higher perception of infant's invasiveness, which in turn was associated with lower presence of meaning. The bootstrapped indirect effect of research group on presence of meaning through marital satisfaction and invasiveness was significant as well $(\beta=0.005, \mathrm{SE}=0.002, \mathrm{BC}$ CI $[0.002,0.11])$, indicating that during the pandemic, mothers reported higher marital satisfaction, which in turn was associated with lower perception of infant's invasiveness, which was associated with greater presence of meaning. Finally, the indirect effect of research group on presence of meaning via marital satisfaction, warmth, and invasiveness was significant, $(\beta=0.0002, \mathrm{SE}=0.0002, \mathrm{BC} \mathrm{CI}$ $[0.0000,0.0007])$. That is, during the pandemic mother's marital satisfaction was higher, which was associated with a higher perception of the infant's warmth, which was associated with a lower perception of infant's invasiveness, which was associated with greater presence of meaning in life.

In respect to search for meaning as well, a significant direct effect was found for research group $(\beta=0.19, \mathrm{SE}=0.09, \mathrm{t}(1133)=2.09, p<0.05)$, with mothers in Group 2 reporting greater search for meaning. Once again, this effect was found insignificant when marital satisfaction and perceptions of infant's warmth and invasiveness were added to the model as mediators, indicating complete mediation. In other words, the total effect was due mainly to these indirect mediations.

Three significant paths of indirect associations were found (Table 4 and Fig. 2). First, the bootstrapped indirect effect of research group on search for meaning through marital satisfaction was significant $(\beta=-0.03, \mathrm{SE}=0.01, \mathrm{BC} \mathrm{CI}[-0.06,-0.01])$, so that during the pandemic mothers reported higher marital satisfaction, which in turn was associated with lower search for meaning. The bootstrapped indirect effect of research group on search for meaning via invasiveness also was significant $(\beta=-0.02, \mathrm{SE}=0.01, \mathrm{BC}$ CI $[0.002,0.04])$. 
Table 4 Total, direct, and indirect effects between group and search for meaning

\begin{tabular}{|c|c|c|c|c|}
\hline & Effect & SE & $\mathrm{t}$ & $95 \% \mathrm{BC} \mathrm{CI}$ \\
\hline Total effect of group on presence of meaning & 0.17 & 0.09 & 1.86 & $-0.009,0.35 \mathrm{~ns}$ \\
\hline Direct effect of group on presence of meaning & 0.19 & 0.09 & $2.09 *$ & $0.01,0.37$ \\
\hline Indirect effect via marital satisfaction & -0.03 & 0.01 & & $-0.06,-0.01$ \\
\hline Indirect effect via infant's warmth & -0.004 & 0.005 & & $-0.01,0.004 \mathrm{~ns}$ \\
\hline Indirect effect via infant's invasiveness & 0.02 & 0.01 & & $0.002,0.04$ \\
\hline Indirect effect via marital satisfaction and infant's warmth & 0.007 & 0.008 & & $-0.0005,0.002 \mathrm{~ns}$ \\
\hline $\begin{array}{l}\text { Indirect effect via marital satisfaction and infant's invasive- } \\
\text { ness }\end{array}$ & -0.004 & 0.002 & & $-0.01,-0.001$ \\
\hline Indirect effect via infant's warmth and invasiveness & 0.001 & 0.001 & & $-0.006, .003 \mathrm{~ns}$ \\
\hline $\begin{array}{l}\text { Indirect effect via marital satisfaction, infant's warmth, and } \\
\text { infant's invasiveness }\end{array}$ & -0.0002 & 0.0002 & & $-0.0006, .0000 \mathrm{~ns}$ \\
\hline
\end{tabular}

$\mathrm{ns}=$ not statistically significant (as evidenced by a bootstrap confidence interval that straddles zero)

$*<0.05$

That is, during the pandemic mothers reported a higher perception of infant's invasiveness, which in turn was associated with higher search for meaning. Finally, the bootstrapped indirect effect of research group on search for meaning through marital satisfaction and invasiveness was significant as well $(\beta=-0.004, \mathrm{SE}=0.002$, BC CI $[-0.01,-0.0 .001])$, indicating that during the pandemic, mothers reported higher marital satisfaction, which was associated with a lower perception of infant's invasiveness, which was associated with lower search for meaning in life.

\section{Discussion}

The current study sought to examine the implications of the COVID-19 pandemic on the presence of meaning and search for meaning of new mothers, along with the contribution of marital satisfaction and perception of the infant. Although the psychological consequences of the current crisis are being investigated (Ahorsu et al., 2020; Choi et al., 2020), the issue of meaning in life has yet to receive more attention. The findings of the present study therefore constitute an important addition to the growing body of knowledge.

The differences found here between the research groups indicate that the level of meaning in life was lower during the pandemic, whereas the level of search for meaning was higher. This is in line with previous studies showing that while the presence of meaning is related to circumstances of well-being and happiness, the search for meaning is a result of stressful situations, such as an external crisis (Boullion et al., 2020; Li et al., 2020). Thus, before the pandemic, mothers tended to experience the highly significant transition to motherhood in a more positive way, with a greater sense that their life was meaningful. However, women experiencing this transition during the pandemic may be more troubled by the stress and ambiguity that characterize the crisis (Chasson et al., 2020; Taubman - Ben-Ari et al., 2020), and more vulnerable to debilitating feelings and an internal need to find meaning in this unprecedented situation.

In addition, differences were found between the groups in the perception of the infant. Whereas before the pandemic mothers reported a greater perception of infant's warmth, 
during the pandemic they reported a greater perception of infant's invasiveness. One possible explanation for this is the psychological distress prevailing during the crisis (Gao et al., 2020; Gómez-Salgado et al., 2020), which may be projected on the infant, and which has been shown to be related to mothers' negative perceptions of the infant (Davies et al., 2008; Lefkovics et al., 2018; Nath et al., 2019). Furthermore, due to the requirement of social distancing, new mothers may be more isolated and have to care for the infant on their own. Unlike the mothers who gave birth before the crisis, they are unable to receive help from their family and social environment or to meet with friends and other mothers. Having to cope with their infant's need in these challenging circumstances may arouse feelings of isolation and despair (Settersten et al., 2020), leading to a more negative perception of the infant.

In contrast to the negative consequences of the current situation on meaning in life and perception of the infant, a higher level of marital satisfaction was reported during the pandemic than prior to it. While dealing with the difficulties generated by the crisis may lead to conflicts and tension in the marital relationship (Prime et al., 2020), it may also bring the couple closer together (Van Bavel et al., 2020). This may be especially significant for new parents, each of whom must adapt to the parental role while at the same time providing and receiving support from the other (Cowan \& Cowan, 2000). Thus, coping jointly with the transition to parenthood, particularly during the crisis, may have strengthened the bond between the couple. In addition, the fact that both spouses stayed at home during the lockdown may have also increased their emotional and instrumental availability to be of help each other, and therefore increased the mothers' marital satisfaction.

As predicted, for the sample as a whole, higher marital satisfaction and perception of infant's warmth were related to higher presence of meaning in life. These findings are consistent with those of previous studies showing the contribution of close relationships and their perception to the sense of meaning in life (Demirbaş-Çelik \& Keklik, 2019; Nelson et al., 2014; O'Donnell et al., 2014). In addition, in the whole sample, associations were found between lower marital satisfaction and perception of infant's invasiveness on the one hand, and higher search for meaning on the other. As noted above, to the best of our knowledge, this is the first time that the connections between these variables and the search for meaning have been examined. Our study suggests that a mother's negative perceptions of her marital relationship and her child may be related to her feeling that something is missing in her life, that it is incomplete in its present form. Consequently, she may look for an explanation or solution that will put these feelings to rest. In other words, she may search for a satisfactory meaning in life.

A number of background variables were also associated here with meaning in life. First, older age correlated with a higher level of presence of meaning, a finding similarly reported by previous studies (Steger et al., 2009). This might be explained by the greater personal and emotional maturity and stability that come with age, which may help to create a stronger sense of the presence of meaning in life. In addition, better economic status was associated with a lower level of search for meaning. It is possible that people who are less preoccupied and stressed by their economic circumstances feel less of a need to look for new or additional meaning in life (Pinquart, 2002). Interestingly, higher level of education was also found to be associated with higher search for meaning. The explanation might lie in the fact that the postpartum period may be characterized by greater conflict and stress for new mothers with more education, as they must now find a way to combine career and professional development with parenting and caring for the baby (Schieman et al., 2009).

The present study highlights the differences between the two groups in respect to the presence of meaning and search for meaning. The findings show that before the pandemic, 
mothers reported greater presence of meaning in life, whereas during the pandemic they reported greater search for meaning. The different patterns of marital satisfaction and perception of the infant might help explain these findings. First, during the crisis, mothers assessed their relationship with their spouse to be more positive and supportive, which contributed to a greater sense of the presence of meaning in life and a lower search for meaning. However, they also perceived the infant to be more invasive, which was found to lead to lower presence of meaning and higher search for meaning.

Moreover, greater marital satisfaction during the pandemic was related to a higher perception of infant's warmth and lower perception of invasiveness, which led to a stronger sense of meaning in life and a lower tendency to search for meaning.

These findings provide an important theoretical insight into possible changes in existential perceptions in a crisis, particularly in the case of new mothers, who are in the midst of a significant life transition and thus subject to two-fold stress. Having to cope with the distress and ambiguity generated by the pandemic appears to have both negative and positive consequences. On the one hand, it reduces the perception of value, direction, and coherence of the current situation and of life in general, leading to the urge to find new meaning in life. This is significant, because the search for meaning has been associated with lower mental health and higher distress (Li et al., 2020; Steger et al., 2008). At the same time, however, the crisis also provides an opportunity to discover or strengthen the mother's positive resources. Thus, when the couple is contending jointly with the difficulties, the woman may experience greater closeness and intimacy with her partner, which is then reflected in a higher perception of warmth from her infant, ultimately leading to a stronger sense of the presence of meaning in life despite the challenging circumstances.

This study has a number of limitations that should be noted. First, it was conducted among Israeli women, most of whom were Jewish, which may limit the generalizability of the results. Although the COVID-19 pandemic is a global crisis, differing medical and cultural characteristics may impact its effect on the existential concerns of new mothers. Thus, further studies examining other populations of new mothers are needed. In addition, we compared two samples of mothers at the same stage of motherhood in two different periods of time, controlling for the demographic differences between them. However, longitudinal studies examining a single sample of new mothers during and after the pandemic might produce additional insights. Finally, we examined the role of marital satisfaction and perception of the infant on new mothers' meaning in life. Future studies might consider the effect of other personal and environmental variables as well.

Nevertheless, the unique design of the present study enabled us to identify differences in meaning in life among new mothers in a crisis situation as opposed to routine times, an issue that has received little attention thus far. The findings show the impact of the COVID19 pandemic on these women, who are at a sensitive and vulnerable stage in their lives. Most importantly, the study demonstrates the crucial role that marital satisfaction and the mother's perception of the infant have on her sense of meaning in life, particularly in a crisis.

Furthermore, the study has significant practical implications. By increasing our understanding of the negative consequences of COVID-19 on new mothers, it provides a basis for the development of interventions to help these women achieve the positive outcome of greater meaning in life. Thus, policymakers and professionals working with women, both routinely and especially in times of crisis and external challenge, would be advised to keep in mind the importance of making room for existential issues, as well as the need for interventions that strengthen the marital and parent-infant relationships. Individual, couple, or group interventions that promote mothers' comprehension of the 
world and of themselves and enhance their positive perceptions of their marital relationship and their infant could augment their feelings of stability and coherence, and consequently increase their sense of the presence of meaning in life and reduce their need to search for meaning. This, in turn, could improve their well-being and the ability to cope with their new role in this challenging and difficult period.

\section{Declarations}

Conflict of interest The authors declare that they have no conflict of interest.

Ethical approval We hereby declare that our article is in compliance with APA ethical standards. Approval of the study protocol was obtained by Institutional Review Board of the School of Social Work at Bar Ilan University.

Informed consent The opening page of the questionnaires states that answering the questionnaires constitute the participant's informed consent to participate in the study.

\section{References}

Ahorsu, D. K., Lin, C. Y., Imani, V., Saffari, M., Griffiths, M. D., \& Pakpour, A. H. (2020). The fear of COVID-19 scale: Development and initial validation. International journal of mental health and addiction. https://doi.org/10.1007/s11469-020-00270-8

Boullion, G. Q., Pavlacic, J. M., Schulenberg, S. E., Buchanan, E. M., \& Steger, M. F. (2020). Meaning, social support, and resilience as predictors of posttraumatic growth: A study of the Louisiana flooding of August 2016. American Journal of Orthopsychiatry, 90(5), 578. https://doi.org/10. 1037/ort0000464

Chasson, M., Taubman - Ben-Ari, O., \& Abu-Sharkia, S. (2020). Jewish and Arab pregnant women's psychological distress during the COVID-19 pandemic: The contribution of personal resources. Ethnicity \& Health. https://doi.org/10.1080/13557858.2020.1815000

Choi, E. P. H., Hui, B. P. H., \& Wan, E. Y. F. (2020). Depression and anxiety in Hong Kong during COVID19. International Journal of Environmental Research and Public Health, 17(10), 3740. https://doi.org/ 10.3390/ijerph17103740

Cowan, C. P., \& Cowan, P. A. (2000). When partners become parents: The big life change for couples. Erlbaum.

Crego, A., Yela, J. R., Gómez-Martínez, M., \& Karim, A. (2020). The contribution of meaningfulness and mindfulness to psychological well-being and mental health: a structural equation model. Journal of Happiness Studies, 21(8), 2827-2850. https://doi.org/10.1007/s10902-019-00201-y

Davies, J., Slade, P., Wright, I., \& Stewart, P. (2008). Posttraumatic stress symptoms following childbirth and mothers' perceptions of their infants. Infant Mental Health Journal, 29(6), 537-554. https://doi. org/10.1002/imhj.20197

Demirbaş-Çelik, N., \& Keklik, İ. (2019). Personality factors and meaning in life: The mediating role of competence, relatedness and autonomy. Journal of Happiness Studies, 20, 995-1013. https://doi.org/ 10.1007/s10902-018-9984-0

Doss, B. D., Rhoades, G. K., Stanley, S. M., \& Markman, H. J. (2009). The effect of the transition to parenthood on relationship quality: An 8-year prospective study. Journal of Personality and Social Psychology, 93, 601-619. https://doi.org/10.1037/a0013969

Gao, J., Zheng, P., Jia, Y., Chen, H., Mao, Y., Chen, S., Wang, Y., Fu, H., \& Dai, J. (2020). Mental health problems and social media exposure during COVID-19 outbreak. PLoS ONE, 15(4), e0231924. https:// doi.org/10.1371/journal.pone.0231924

Gómez-Salgado, J., Andrés-Villas, M., Domínguez-Salas, S., Díaz-Milanés, D., \& Ruiz-Frutos, C. (2020). Related health factors of psychological distress during the COVID-19 pandemic in Spain. International Journal of Environmental Research and Public Health, 17(11), 3947. https://doi.org/10.3390/ ijerph17113947 
Goodman, M. L., Gibson, D. C., Keiser, P. H., Gitari, S., \& Raimer-Goodman, L. (2019). Family, belonging and meaning in life among semi-rural Kenyans. Journal of Happiness Studies, 20(5), 1627-1645. https://doi.org/10.1007/s10902-018-0017-9

Hayes, A. F. (2017). Introduction to mediation, moderation, and conditional process analysis: A regressionbased approach. Guilford!?

Hendrick, S. S. (1988). A generic measure of relationship satisfaction. Journal of Marriage and the Family, 50(1), 93-98. https://doi.org/10.2307/352430

Kalantarkousheh, S. M., \& Hassan, S. A. (2010). Function of life meaning and marital communication among Iranian spouses in Universiti Putra Malaysia. Procedia-Social and Behavioral Sciences, 5, 1646-1649. https://doi.org/10.1016/j.sbspro.2010.07.340

Keizer, R., \& Schenk, N. (2012). Becoming a parent and relationship satisfaction: A longitudinal dyadic perspective. Journal of Marriage and Family, 74, 759-773. https://doi.org/10.1111/j.1741-3737.2012. 00991.x

Leavitt, C. E., McDaniel, B. T., Maas, M. K., \& Feinberg, M. E. (2017). Parenting stress and sexual satisfaction among first-time parents: A dyadic approach. Sex Roles, 76, 346-355. https://doi.org/10.1007/ s11199-016-0623-0

Lefkovics, E., Rigó, J., Jr., Kovács, I., Talabér, J., Szita, B., Kecskeméti, A., Szabó, L., Somogyváril, Z., \& Baji, I. (2018). Effect of maternal depression and anxiety on mother's perception of child and the protective role of social support. Journal of Reproductive and Infant Psychology, 36(4), 434-448. https:// doi.org/10.1080/02646838.2018.1475726

Li, J., Dou, K., \& Liang, Y. (2020). The relationship between presence of meaning, search for meaning, and subjective well-being: A three-level meta-analysis based on the meaning in life questionnaire. Journal of Happiness Studies. https://doi.org/10.1007/s10902-020-00230-y

McDonald, S., Slade, P., Spiby, H., \& Iles, J. (2011). Post-traumatic stress symptoms, parenting stress and mother-child relationships following childbirth and at 2 years postpartum. Journal of Psychosomatic Obstetrics \& Gynecology, 32(3), 141-146. https://doi.org/10.3109/0167482X.2011.596962

Mickelson, K. D., \& Joseph, J. A. (2012). Postpartum body satisfaction and intimacy in first-time parents. Sex Roles, 67, 300-310. https://doi.org/10.1007/s11199-012-0192-9

Morse, J. L., \& Steger, M. F. (2019). Giving birth to meaning: Understanding parenthood through the psychology of meaning in life. In O. Taubman - Ben-Ari (Ed.), Pathways and barriers to the transition to parenthood - Existential concerns regarding fertility, pregnancy, and early parenthood. Springer. https://doi.org/https://doi.org/10.1007/978-3-030-24864-2_1

Nath, S., Pearson, R. M., Moran, P., Pawlby, S., Molyneaux, E., Challacombe, F. L., \& Howard, L. M. (2019). The association between prenatal maternal anxiety disorders and postpartum perceived and observed mother-infant relationship quality. Journal of Anxiety Disorders, 68, 102148. https://doi.org/ 10.1016/j.janxdis.2019.102148

Nelson, S., Kushlev, K., \& Lyubomirsky, S. (2014). The pains and pleasures of parenting: When, why, and how is parenthood associated with more or less well-being? Psychological Bulletin, 140(3), 846-895. https://doi.org/10.1037/a0035444

Oates, J., \& Gervai, J. (2019). Mothers' perceptions of their infants. Journal of Prenatal \& Perinatal Psychology \& Health, 33(4), 282-300.

Oates, J., Gervai, J., Danis, I., Lakatos, K., \& Davies, J. (2018). Validation of the Mothers' object relations scales short-form (MORS-SF). Journal of Prenatal and Perinatal Psychology and Health, 33(1), 38-50.

O’Donnell, M. B., Bentele, C. N., Grossman, H. B., Le, Y., Jang, H., \& Steger, M. F. (2014). You, me, and meaning: An integrative review of connections between relationships and meaning in life. Journal of Psychology in Africa, 24(1), 44-50. https://doi.org/10.1080/14330237.2014.904097

Pinquart, M. (2002). Creating and maintaining purpose in life in old age: A meta-analysis. Ageing International, 27, 90-114. https://doi.org/10.1007/s12126-002-1004-2

Prime, H., Wade, M., \& Browne, D. T. (2020). Risk and resilience in family well-being during the COVID19 pandemic. American Psychologist, 75, 631-643. https://doi.org/10.1037/amp0000660

Schieman, S., Glavin, P., \& Milkie, M. A. (2009). When work interferes with life: Work-nonwork interference and the influence of work-related demands and resources. American Sociological Review, 74(6), 966-988. https://doi.org/10.1177/000312240907400606

Schulz, M., Cowan, C. P., \& Cowan, P. A. (2006). Promoting healthy beginnings: A randomized controlled trial of a preventive intervention to preserve marital quality during the transition to parenthood. Journal of Consulting \& Clinical Psychology, 74, 20-31. https://doi.org/10.1037/0022-006X.74.1.20

Settersten, R., Bernardi, L., Harkonen, J., Antonucci, T.C., Dykstra, P.A., Heckhausen, J., Kuh, D., Mayer, K. U., Moen, P., Mortimer, J., Mulder, C., Smeeding, T. M., van der Lippe, T., Hagestad, G. O., Kohli, M., Levy, R., Schoon, I., \& Thomson, E. (2020). Understanding the effects of COVID-19 through a 
life course lens. Advances in Life Course Research, 45. early access. https://doi.org/https://doi.org/10. 1016/j.alcr.2020.100360

Slade, A., Grienenberger, J., Bernbach, E., Levy, D., \& Locker, A. (2005). Maternal reflective functioning, attachment, and the transmission gap: A preliminary study. Attachment \& Human Development, 7(3), 283-298. https://doi.org/10.1080/14616730500245880

Steger, M. F., Frazier, P., Oishi, S., \& Kaler, M. (2006). The meaning in life questionnaire: assessing the presence of and search for meaning in life. Journal of Counseling Psychology, 53(1), 80-93. https:// doi.org/10.1037/0022-0167.53.1.80

Steger, M. F., Kashdan, T. B., Sullivan, B. A., \& Lorentz, D. (2008). Understanding the search for meaning in life: Personality, cognitive style, and the dynamic between seeking and experiencing meaning. Journal of Personality, 76(2), 199-228. https://doi.org/10.1111/j.1467-6494.2007.00484.x

Steger, M. F., Oishi, S., \& Kashdan, T. B. (2009). Meaning in life across the life span: Levels and correlates of meaning in life from emerging adulthood to older adulthood. The Journal of Positive Psychology, 4(1), 43-52. https://doi.org/10.1080/17439760802303127

Taubman - Ben-Ari, O., Shlomo, S. B., \& Findler, L. (2012). Personal growth and meaning in life among first-time mothers and grandmothers. Journal of Happiness Studies, 13(5), 801-820.

Taubman - Ben-Ari, O., Chasson, M., Abu-Sharkia, S., \& Weiss, E. (2020). Distress and anxiety associated with COVID-19 among Jewish and Arab pregnant women in Israel. Journal of Reproductive and Infant Psychology, 38(3), 340-348. https://doi.org/10.1080/02646838.2020.1786037

Trzebiński, J., Cabański, M., \& Czarnecka, J. Z. (2020). Reaction to the COVID-19 pandemic: The influence of meaning in life, life satisfaction, and assumptions on world orderliness and positivity. Journal of Loss and Trauma, 21, 1-14. https://doi.org/10.1080/15325024.2020.1765098

Van Bavel, J. J., Baicker, K., Boggio, P. S., Capraro, V., Cichocka, A., Cikara, M., \& Willer, R. (2020). Using social and behavioural science to support COVID-19 pandemic response. Nature Human Behavior, 4(5), 460-471. https://doi.org/10.1038/s41562-020-0884-z

Van Tongeren, D. R., Aten, J. D., Davis, E. B., Davis, D. E., \& Hook, J. N. (2017). Religion, spirituality, and meaning in the wake of disasters. In S. E. Schulenberg (Ed.). Positive psychological approaches to disaster (pp. 27-44). Springer.

Publisher's Note Springer Nature remains neutral with regard to jurisdictional claims in published maps and institutional affiliations. 